\title{
Moving Toward a Collective Impact Effort: The Volunteer Program Assessment
}

\author{
Sheridan Trent, Kelly Prange, and Joseph A. Allen
}

\begin{abstract}
Volunteers are essential to the operation of many nonprofits, but some experience challenges in retaining their volunteer workforce. The Volunteer Program Assessment (VPA) seeks to address this issue by helping organizations to identify strengths, growth areas, and recommendations for improving volunteer experiences. To maximize the effectiveness of VPA's mission, the organization is moving toward a collective impact (CI) approach. Although not developed as a CI effort, the program currently exemplifies many of its characteristics, which have been instrumental in expanding reach to more organizations. We examine VPA's alignment with collective impact and outline how VPA will continue to improve efforts.
\end{abstract}

Keywords: Volunteerism; university programs; evaluation; industrial-organizational psychology

\section{Introduction}

When utilized strategically, volunteers provide a critical support to organizations, such as assisting with fundraising efforts, collection and distribution of donated goods, youth mentoring, coaching, tutoring, administrative tasks, and general labor. According to the Corporation for National and Community Service (2016), volunteers contributed 7.9 billion hours of service and saved $\$ 184$ billion for nonprofits in the United States in 2015. Volunteers are almost twice as likely to donate financially to their organizations as non-volunteers (Corporation for National and Community Service, 2016).

Given the positive impact of volunteers on organizations, it is critical for programs to retain them. Unfortunately, many nonprofit organizations experience significant challenges in managing their volunteers effectively, with approximately one-third of volunteers discontinuing service in the first year (Davis, Hall, \& Meyer, 2003), representing a loss of \$38 billion dollars in labor (Eisner, Grimm Jr., Maynard, \& Washburn, 2009). Thus, the declining rates of volunteerism across the United States are a growing problem for the organizations that depend on volunteer efforts for sustainability. In examining why volunteers leave, several explanations have been put forth by researchers. A study conducted in 2003 by the Corporation for National and Community Service found a number of factors implicated in the discontinuation of volunteer service, most notably centered on a lack of adoption of effective volunteer management practices. For example, the only management practice widely adopted by volunteer organizations was that of providing regular supervision and communication with volunteers, with $67 \%$ of organizations indicating that they performed this activity to a large degree. However, practices such as offering training to volunteers, having written policies and job descriptions for volunteer involvement, and conducting recognition activities for volunteers were adopted much less frequently, indicating that the adoption of practices to help effectively run volunteer programs are limited and still represent a significant problem for many organizations. 
In 2016, the President of the Society for Industrial-Organizational Psychology (SIOP), Steve Kozlowski, charged industrial-organizational (I-O) psychologists to use their skills to advance efforts supporting advocacy and community impact. The SIOP contains academics and practitioners with expertise in organizational development, human resources management, evaluation, and others that are relevant to the nonprofit management and development. One such initiative, the Volunteer Program Assessment (VPA), was highlighted as an example of how I-O psychologists can have a substantial impact in their communities. Established in 2009, the VPA is a collaboration between six universities across the United States with the common mission of improving nonprofit organizational effectiveness: (1) the University of Nebraska at Omaha, (2) the University of North Carolina at Charlotte, (3) the University of South Florida, (4) George Mason University, (5) the University of Northern Illinois, and (6) Illinois State University. With the support of their respective Universities, each VPA chapter has grown and developed individually.

However, the overarching structure of VPA, along with its shared goals and mission, is capable of supporting a collective impact approach. Many collective impact articles have highlighted the importance of developing collective impact efforts from the beginning of a project. However, we demonstrate that with a certain level of growth and collaboration, some organizations may develop into collective impact initiatives by necessity. By moving toward a collective impact approach, VPA has been able to serve more than 300 nonprofit organizations and made great strides in improving organizational capacity and volunteer satisfaction and retention.

This paper describes how VPA, grounded within each chapter's respective university system, has utilized the collective impact model to serve a greater number of clientele, serve clientele more effectively, and have a broader impact. In this article, we will depict the ongoing evolution of VPA from independent chapters to a unified set of organizations with aligned goals. We will briefly review the key tenets of collective impact, explain why a collective impact approach is valuable in this case, and discuss the steps VPA has taken in recent years to move toward a collective impact effort.

\section{What is the VPA?}

Efforts to help build the capacity of volunteer programs are not new; there are multiple organizations that either distribute resources for volunteers, or help to build their capacity in other ways. One example of such an organization is Points of Light, a national group who assists nonprofits in a multitude of ways. These include connecting those interested in service with volunteer opportunities, highlighting tools organizations can use for recruitment, background checking, and training, and helping companies to launch volunteer programs for employees (Points of Light: What We Do for Nonprofits, n.d.). Another organization providing similar services is the Nonprofit Association of the Midlands, which distributes information to members about educational opportunities for program managers, provide managers with toolkits to address a variety of issues, and help to connect nonprofit leaders with others in the community (Nonprofit Association of the Midlands, n.d.). In contrast to these approaches, VPA chapters are not independent organizations, but rather groups connected to their respective universities, which function as anchor institutions, providing spatial immobility, corporate status, scale, and a 
common mission of social justice, democracy, and equity (Fulbright-Anderson, Auspos \& Anderson, 2001).

\section{History of VPA}

VPA was founded by Dr. Steven Rogelberg, Dr. Joseph Allen, and Dr. Daniel Bonilla, after their results of a study of animal welfare volunteers revealed a critically unmet need for assessment resources in the volunteer sector. Continued and more recent investigations into the state of volunteering in the United States paints a similar picture, with the rate of volunteering decreasing each year (Bureau of Labor Statistics, 2016). With the goal of addressing this problem, by providing program coordinators with feedback and key insights from the perspective of their volunteers, the VPA was launched in 2009 at the University of North Carolina Charlotte. The program continues to operate to this day, and has expanded to five other chapters across the United States.

In 2013, Dr. Joseph Allen brought the VPA to the University of Nebraska at Omaha. Shortly after VPA began operating at UNO, the organization applied for, and received, space in UNO's newly-built Weitz Community Engagement Center, a 70,000 square foot facility in the middle of UNO's campus. The Center houses over thirty university and community organizations and provides nonprofit organizations with space to fulfill their missions and foster collaborations. With the new space, VPA-UNO utilized its new resources by training more students in consulting practices, and has grown its client base by $300 \%$ in three years.

What is VPA?

VPA is a capacity-building and philanthropic organization dedicated to helping nonprofit agencies, consisting of industrial-organizational psychology faculty and graduate students, as well as undergraduate students from multiple majors in a single University. The VPA serves nonprofits by assessing the experiences of their volunteers to improve volunteer satisfaction, performance, and retention. Using the results of the assessment, student analysts develop comprehensive diagnostic reports, prepare interpretations of these reports, and meet with leaders from client organizations to provide consultations and guidance for improving volunteers' experiences. If these services were provided at market value, organizations might pay approximately $\$ 10,000$ for the survey alone, excluding interpretation and consultation; however, VPA provides these services completely free-of-charge as a community service.

In return, the VPA provides its students with the opportunity to gain skills and knowledge through experiential learning. The VPA gives both undergraduate and graduate students the opportunity to experience co-curricular service throughout their college career by applying the skills they learn in their classes to help volunteer managers. Students have direct contact with volunteer program managers in their community and across the country, and they apply interdisciplinary knowledge from psychology, organizational development, business management, communications, technology, and nonprofit management. The VPA follows tenets of experiential learning and quality education practices such as: (a) reciprocity, in which both the receiver of the service and the giver of the service learn from the exchange; (b) reflection on their learning; and (c) giving students autonomy and voice in their learning (Billings, 2006; 
Scales, Roehlkipartain, Neal, Kielsmeier, \& Benson, 2006). Students can utilize their current skills when working with clients and integrate new, practical knowledge about the nonprofit industry into their current understanding of their role within the community. Because students give their time to each client for free, they also feel satisfied that they give valuable data and consulting services to volunteer programs that otherwise could not afford to buy those services. As previously stated, the program's reciprocal nature ensures that all parties benefit from the exchange of resources.

\begin{tabular}{l|l|}
$\begin{array}{l}\text { Table 1. Kania \& Kramer's Characteristics of Successful Collective Impact Initiatives } \\
\text { Common Agenda }\end{array}$ & $\begin{array}{l}\text { All participants have a shared vision for change including a common } \\
\text { understanding of the problem and a joint approach to solving it through } \\
\text { agreed upon actions. }\end{array}$ \\
$\begin{array}{l}\text { Shared } \\
\text { Measurement } \\
\text { Systems }\end{array}$ & $\begin{array}{l}\text { Collecting data and measuring results consistently across all participants } \\
\text { ensures efforts remain aligned and participants hold each other } \\
\text { accountable. }\end{array}$ \\
$\begin{array}{l}\text { Mutually } \\
\text { Reinforcing } \\
\text { Activities }\end{array}$ & $\begin{array}{l}\text { Participant activities must be differentiated while still being coordinated } \\
\text { through a mutually reinforcing plan of action. }\end{array}$ \\
$\begin{array}{l}\text { Continuous } \\
\text { Communication } \\
\text { Backbone Support } \\
\text { Organizations }\end{array}$ & $\begin{array}{l}\text { Consistent and open communication is needed across the many players } \\
\text { to build trust, assure mutual objectives, and create common motivation. }\end{array}$ \\
$\begin{array}{l}\text { Creating and managing collective impact requires a separate } \\
\text { organization with staff and a specific set of skills to serve as the } \\
\text { backbone for the entire initiative and coordinate participating } \\
\text { organizations and agencies. }\end{array}$
\end{tabular}

\section{Adapted from Kania \& Kramer, 2013}

Other VPA chapters have also developed in response to ongoing interest and demand in the program. In addition to VPA-UNO, VPA began working with partners at George Mason University, Illinois State University, the University of South Florida, and Northern Illinois University over the past few years (Olien et al., 2014). Development of a VPA chapter requires only interest from a university faculty member, and completion of a training process, which is provided by the founding VPA chapter in Charlotte. In addition to training, the Charlotte chapter also helps new chapters in setting up the VPA assessment, provides all necessary process documents for conducting the assessment, collects and manages data from all VPA chapters, and aids in the procurement of client organizations. There are currently six VPA groups operating across the United States, serving more client organizations each year. As VPA groups have expanded, keeping up with client demand as well as working out the most effective practices for maintaining the program has involved a considerable amount of collaboration between chapters. In addition to cross-chapter collaboration, VPA groups are increasingly finding ways to work more collaboratively with client organizations to best meet their needs. This necessary upsurge in collaboration has led to increasing discussion as to whether VPA groups would function more effectively by utilizing a collective impact approach, as well as whether VPA groups are in fact already utilizing a collective impact approach. 


\section{Collective Impact}

In the seminal article, Kania and Kramer (2011) describe collective impact as an emerging strategy to help address complex social issues more effectively. The benefit of a collective impact approach lies in that it reduces the amount of overlap between organizations attempting to address the same goal, and also allows for the sharing of information between different 'actors' to target an issue on different levels. Their seminal article provided a definition of collective impact that included five key characteristics necessary for a successful outcome: (a) a common agenda; (b) shared measurement systems; (c) mutually reinforcing activities; (d) continuous communication; and (e) backbone support organizations. Each characteristic allows actors from different sectors to work together to solve a specific social problem (see Table 1 for definitions). An update by Kania, Hanleybrown, and Splansky Juster (2014) also described three important mindset shifts necessary for successful implementation of collective impact. These include getting the correct people involved to help a specific problem, having collaborators change the way they work with each other, and understanding that social issues relentlessly change and solutions must adapt to changes.

Although the term 'collective impact' is increasing in popularity, many agree that true collective impact initiatives which meet all five criteria are rare (Kania \& Kramer, 2011), and that the term is sometimes applied to initiatives which do not fully meet the criteria (Prange, Allen, \& ReiterPalmon, 2016). Reasons for the incorrect labeling may have to do with a lack of full understanding as to what is needed to carry out a collective impact effort, or a general lack of clarity as to the five tenets outlined by Kania and Kramer (2011).

A precondition noted by some researchers is that many successful collective impact initiatives are designed and planned specifically to constitute a collective impact approach, with a heavy focus on assessment (Parkhurst \& Preskill, 2014; Prange, Allen, \& Reiter-Palmon, 2016). One important question, which has not yet been explored in case studies, is whether it is possible for an organization to move from a collaborative initiative to a collective impact initiative in order to have a broader impact, and what such a shift might look like. Another question not yet answered is whether it is possible for a collaborative effort to shift organically into a collective impact effort over time. Flood et al. (2015) noted in a recent case study that although key stakeholders did not intentionally seek out collective impact as a model for an initiative to address health issues in a neighborhood in San Francisco, the approach was later noted by many to align closely with collective impact. Furthermore, some researchers have noted that collective impact may simply be another form of inter-organizational collaboration (Prange, Allen, \& Reiter-Palmon).

\section{Why Collective Impact?}

Multiple researchers have expounded the benefits of a collective impact approach. By taking a collective impact approach, social change agents/organizations can tackle a particular issue together rather than separately. By aligning their goals, methods, and evaluation in solving a social issue, multiple actors can be more effective in facilitating change than if they were each trying to solve issues without continuous collaboration. Collective impact initiatives such as Strive, Shape up Somerville, Mars, and the Elizabeth R. Project, were cited as very successful examples, by Kania and Kramer (2011) in their seminal article on collective impact. Flood et al., 
(2015), researching the efforts in the health services sector, found collective impact to be extremely useful in attempting to address poor health and nutrition in a San Francisco neighborhood.

Although researchers in general have articulated the benefit of collective impact through experience and theory, Kania and Kramer (2011) suggested that collective impact is likely most useful when addressing problems that are more adaptive. That is, collective impact can be most successful in generating solutions for social issues that are complex, in which the solution is not well-known or cannot be easily implemented. Volunteer program effectiveness is one issue sufficiently complex to warrant individuals from different agencies working together. There are a few reasons for this. First, there is no 'one size fits all' solution to address program challenges. Although volunteer programs have one thing in common (i.e., volunteers), they differ drastically in terms: (a) size, ranging from as few as five volunteers to thousands of volunteers; (b) staff, with some programs being entirely volunteer-operated and some having a large, dedicated paid staff; (c) type of service, with some volunteers performing administrative work, some volunteers engaged in fundraising efforts, some volunteers doing direct service, and some volunteers whose experiences include all of these types of service and more; (d) funding, as some programs are well-funded and some extremely limited,;(e) volunteer demographics, with some organizations comprised mostly of elderly volunteers, some mostly of college students, and some with more diverse volunteer populations; (f) volunteer manager capability, with some volunteer coordinators whose entire job is to ensure the volunteer program is running efficiently, and others who may only dedicate a small percentage of their time toward managing the volunteer program; and (g) board coordination, with some programs being accountable and having the support of a board, and others that do not.

These, which are in no way an exhaustive list, render it extremely difficult to simply put out 'solutions' and recommend that all programs implement them regardless of their individual characteristics or ability to do so. Additionally, it is impossible to take considerations like this into account without working closely with managers and paid staff at volunteer organizations to develop useful recommendations tailored to their program. This point has become increasingly salient for VPA chapters as the organization has evolved. Collaborating with other chapters in finding ways to better serve client organizations has also been necessary, in order to tackle ongoing organizational challenges such as dealing with rapid program growth, modifying training procedures as necessary in response to student analyst feedback, and implementing new procedures piloted at different chapters to better address client needs. Problems faced by one chapter are typically experienced at other chapters as well, so such an approach saves time and resources that can be better spent toward serving client organizations, which is crucially important for VPA chapters who typically have lengthy waitlists. Thus, it is not so much a choice to begin relying on cross-sector coordination, which begins to resemble collective impact, to operate efficiently as it is necessary for program survival. 


\section{Moving Towards Collective Impact}

The six chapters of VPA are a collective of organizations trying to simultaneously improve volunteer program effectiveness across the United States. Though the initial founding members did not envision VPA as a collective impact operation, continued functioning of the organization, as well as the need to serve client organizations as effectively as possible, have necessitated that the organization develop into a collective impact effort. To highlight the similarities and differences between VPA and more traditional collective impact initiatives, the various tenets of collective impact as well as how VPA aligns with those characteristics are discussed below.

\section{A Common Agenda}

The importance of a common agenda has been highlighted as critical by those utilizing collective impact (Flood et al., 2015; Hanleybrown, Kania, \& Kramer, 2012). Researchers studying collective impact to date have described achieving a common agenda as a potentially challenging but necessary activity involving the agreement of all stakeholders, which can include dozens or more organizations working in tandem (Kania \& Kramer, 2011). Volunteer Program Assessment groups share the same common agenda of improving volunteer program effectiveness. Although there are differences by chapter with regard to the type of volunteer research conducted, what organizations each chapter reach out to, and occasionally the development of unique processes to address specific programmatic challenges, the core agenda remains the same and in alignment with previous collective impact efforts.

Different from these efforts is that VPA includes agreement of a common agenda among six affiliate organizations and the client organizations they serve, while other collective impact initiatives typically involve more stakeholders (Kania \& Kramer, 2011). In spite of a reduced number of stakeholders involved with the agenda, throughout the expansion of VPA from a single university setting to six individual chapters, the need to reinforce a common agenda and continuously commit to the central mission of VPA has become more relevant of late, and is more difficult to accomplish from different physical locations. Thus, in contrast to the beginning of VPA, reinforcement of a common agenda is now accomplished through several mechanisms.

First, VPA chapters re-visit goals and align their purpose formally on an annual basis through a conference call with key stakeholders, an initiative started in 2013. In each yearly call, critical updates and information are shared, such as important insights, process changes, and collaborative progress with clients. In addition to the yearly call, it has become clear that chapters benefit even more from in-person interaction than simple phone calls. Thus, starting in the spring of 2015, representatives from each VPA chapter attend an in-person meeting at the annual SIOP (Society for Industrial-Organizational Psychologists) conference, bringing together student volunteers from different chapters, as well as VPA faculty directors. The agenda of the annual conference meeting is to provide an update on client activities in the past year, discuss unique challenges that came up and how they addressed such challenges, and to share meaningful experiences. This in-person venue also allows for students and faculty from different universities to discuss their experiences together and share ideas amongst themselves. 
In addition to these two formal mechanisms created to maintain a common agenda, VPA directors remain in close contact about ideas needed to stay on-track and improve the VPA process through email and phone contact, as well as by collaborating on other projects. Several VPA chapters have also begun utilizing social media as recently as 2016, to share information and resources between chapters. Some of the updates stemming from ideas discussed during the annual meeting have led to implementation of new initiatives at all chapters. These include expanding one of the VPA survey items about gender to better reflect gender identity concerns from clients, incorporating a post-survey satisfaction questionnaire to all clients to make sure we are meeting their needs and soliciting feedback, and updating job descriptions of key VPA personnel (e.g., student assistant directors and volunteers). These reforms were all incorporated into the VPA chapters throughout 2016.

\section{Shared Measurement Systems}

There are three cross-chapter measurement systems used by VPA, which were in use at the founding chapter, and have been expanded to other chapters in the years since. First, all VPA chapters track the number of clients served each year in the same way, through the use of a client log spreadsheet which contains information about client organizations' name, location, contact info, how many times the client has conducted VPA at their organization, and notes. This system is used to provide an update each year at the annual SIOP conference meeting. VPA chapters also use the same standardized VPA survey itself, which enables each chapter to track key indicators of client success such as volunteer satisfaction, volunteer engagement, and volunteer continuance.

Finally, in creating standards to assess impact, VPA chapters pool their data files every two years. The data is then compiled and then distributed by the founding chapter to create national norms. The advantage of having a national 'standard' is that chapters can use the information to compare meaningfully against new client's VPA results and identify areas in which the organization's volunteers are similar to other volunteers, as well as to identify areas in which the client organization's volunteers are reporting lower scores. This shared norming system ensures that all VPA chapters have the same benchmarks against which to compare client results. Due to the large amount of data collected from client organizations, a recent development in this area, which occurred in 2014, has been the development of specific norms by volunteer category. Currently, VPA chapters have normative scores for volunteers serving in animal welfare, arts and educational groups, health and human services, and police, fire, and rescue volunteer organizations.

These shared measurement systems are certainly in alignment with past collective impact approaches, which have included similar systems such as: (a) evaluating progress based off of previously developed and agreed upon criteria, as well as the same outcomes (e.g., Strive, Edmondson \& Santhosh-Kumar, 2017; Kania \& Kramer, 2011); (b) coming together to create shared definitions and understanding (e.g., Calgary Homeless Foundation, Hanleybrown, Kania, \& Kramer, 2012); and (c) developing ways to measure success while taking into account the context of the evaluation (e.g., Shape Up Somerville, Parkhurst \& Preskill, 2014). 
There is a high degree of overlap between the activities conducted at each VPA chapter, which is different from other collective impact initiatives that tend to involve more diverse activities (Kania \& Kramer, 2011). Although there are advantages to this approach, in that the activities of VPA chapters are inherently mutually reinforcing, ultimately this is not consistent with the vision of collective impact, which stresses different stakeholders with different sets of expertise, who are leveraging their individual strengths to create change. However, one redeeming factor is that each chapter has different strengths. Out of these strengths, new ideas to improve best practices, and new materials to help track and keep organized, are frequently developed and shared. For example, some chapters have had more success in drumming up program interest than others, and strategies for identifying new client organizations to work with are shared with chapters that may be struggling. Furthermore, having chapters in multiple locations across the country allows VPA groups to distribute the client workload by passing new clients to other chapters if a certain chapter is already at capacity for the semester. This allows VPA to serve as many clients as possible each semester.

\section{Continuous Communication}

Without continuous communication, both formal and informal, the other tenets of collective impact such as maintaining a common agenda, utilizing shared measurement systems, and conducting mutually reinforcing activities would not be possible. Thus, communication across VPA affiliates occurs in multiple ways (e.g., conference calls, in-person meeting, or emails) as well as multiple time points throughout the year. The different VPA chapters may serve different types of organizations, based on their geography and the major industries in their cities. For example, the chapter at North Carolina at Charlotte serves many animal shelter organizations. It has created a unique process to serve those clients, as well as distributed new information to other chapters in 2016 regarding the lessons they have learned about those organizations. Even though the chapters may focus on different nonprofit industries and/or organizations, the continuous communication between chapters keeps them aligned.

\section{Backbone Support Organizations.}

This is the main area in which VPA does not resemble a collective impact approach. Although some affiliates have secured support from their universities (e.g., VPA-UNO maintains office space in UNO's Community Engagement Center) or grant funding (e.g., VPA UNCC operates on a grant from the Humane Society of the United States), others operate on an entirely volunteer basis without any paid staff. Given the important role backbone organizations play in maintaining collective impact efforts (Hanleybrown, Kania, \& Kramer, 2012; Turner, Merchant, Kania, \& Martin, 2012), this lack represents a substantial challenge for the sustainability of VPA. Thus, one of the main goals of VPA moving forward is to find consistent support for each VPA chapter to fund both students and program operating costs, or finding a common source for funding that could be split between the six chapters.

The VPA and its chapters already have a core mission (i.e., agenda) and a clear strategy for how to go about increasing volunteer program effectiveness-through the use of surveys and 
consulting that is given free-of-charge to organizations with volunteers (i.e., mutually reinforcing activities). The surveys we deploy with our client organizations are a perfect example of a shared measurement system, however, we need to improve upon our measurement by focusing on other outcomes of the VPA, such as student analyst learning and development. In addition, continuing to facilitate ongoing communication between the chapters will take effort. However, the most important action VPA can take to fully committing to collective impact will be to find a source or multiple sources of funding to cover administrative expenses.

\section{The Impact of VPA}

Through the use of collective impact practices so far, Volunteer Program Assessment has made notable gains in improving nonprofit organizational effectiveness using several shared metrics, including program capacity, volunteer satisfaction, and volunteer continuance intentions. To date, VPA has conducted over 300 assessments, providing $\$ 4.5$ million of in-kind services to nonprofits. The three areas in which VPA partner organizations have improved over time are described below as well as some examples of each metric.

\section{Increased Volunteer Program Capacity of Partner Organizations}

As VPA works with clients over time, we track their changes to provide a year to year comparison of each area of the survey. Although it is not always possible for client organizations to implement every change or best practice that VPA recommends each year, we have found overwhelmingly that when organizations are able to devote time and effort toward addressing growth areas, such growth areas tend to improve. Some of the documented efforts of client organizations as well as the resulting improvement found from the VPA survey are noted in Table 2 below. 
Table 2. Program Changes and Score Improvements

\begin{tabular}{|c|c|c|c|c|}
\hline $\begin{array}{c}\text { Organization } \\
\text { Type }\end{array}$ & $\begin{array}{l}\text { Growth } \\
\text { Area }\end{array}$ & $\begin{array}{l}\text { Time 1* } \\
\text { Score }\end{array}$ & $\begin{array}{l}\text { Time 2* } \\
\text { Score }\end{array}$ & Changes Made: \\
\hline $\begin{array}{l}\text { Music Education } \\
\text { Youth } \\
\text { Development } \\
\text { Program }\end{array}$ & Recognition & 60 & 90 & $\begin{array}{l}\text { Began ending each concert/event } \\
\text { by thanking all volunteers. } \\
\text { Personalized thank you notes } \\
\text { written to all parent volunteers } \\
\text { who went above and beyond } \\
\text { during the season. }\end{array}$ \\
\hline $\begin{array}{l}\text { Nutrition and } \\
\text { Health } \\
\text { Education } \\
\text { Program }\end{array}$ & $\begin{array}{l}\text { Perception } \\
\text { of Voice }\end{array}$ & 69 & 86 & $\begin{array}{l}\text { Shared the results of the VPA } \\
\text { survey with volunteers and asked } \\
\text { for feedback. }\end{array}$ \\
\hline $\begin{array}{l}\text { Regional } \\
\text { Foodbank }\end{array}$ & $\begin{array}{l}\text { Perception } \\
\text { of Voice }\end{array}$ & 44 & 66 & $\begin{array}{l}\text { Shared the results of the VPA } \\
\text { survey with volunteers and asked } \\
\text { for feedback. }\end{array}$ \\
\hline $\begin{array}{l}\text { Youth } \\
\text { Mentoring and } \\
\text { Development } \\
\text { Program }\end{array}$ & $\begin{array}{l}\text { Satisfaction } \\
\text { with } \\
\text { Volunteer } \\
\text { Colleagues }\end{array}$ & 86 & 99 & $\begin{array}{l}\text { Brought volunteers together for } \\
\text { volunteer appreciation luncheon } \\
\text { incorporating VPA results and } \\
\text { Q\&A session. }\end{array}$ \\
\hline $\begin{array}{l}\text { Youth Advocacy } \\
\text { Program }\end{array}$ & Recognition & 84 & 92 & $\begin{array}{l}\text { Implementation of a new } \\
\text { recognition program for } \\
\text { volunteers. }\end{array}$ \\
\hline $\begin{array}{l}\text { Midwest } \\
\text { Hospital System }\end{array}$ & $\begin{array}{l}\text { Satisfaction } \\
\text { with Paid } \\
\text { Staff }\end{array}$ & 75 & 83 & $\begin{array}{l}\text { Hiring of a specific coordinator to } \\
\text { better support the program. }\end{array}$ \\
\hline
\end{tabular}

Enhanced Satisfaction of Volunteers at Partner Organizations

VPA collects several sources of information regarding volunteers' satisfaction with their experiences, including satisfaction regarding their interpersonal perceptions with others at the organization, satisfaction with the flow of communication coming from the organization, satisfaction with the contribution they feel they have been able to make to the organization, and overall satisfaction with their volunteer work. An aggregated measure of satisfaction including several of these categories of satisfaction is included below, with most organizations finding that their volunteers experience increased satisfaction each year they have participated with VPA. 


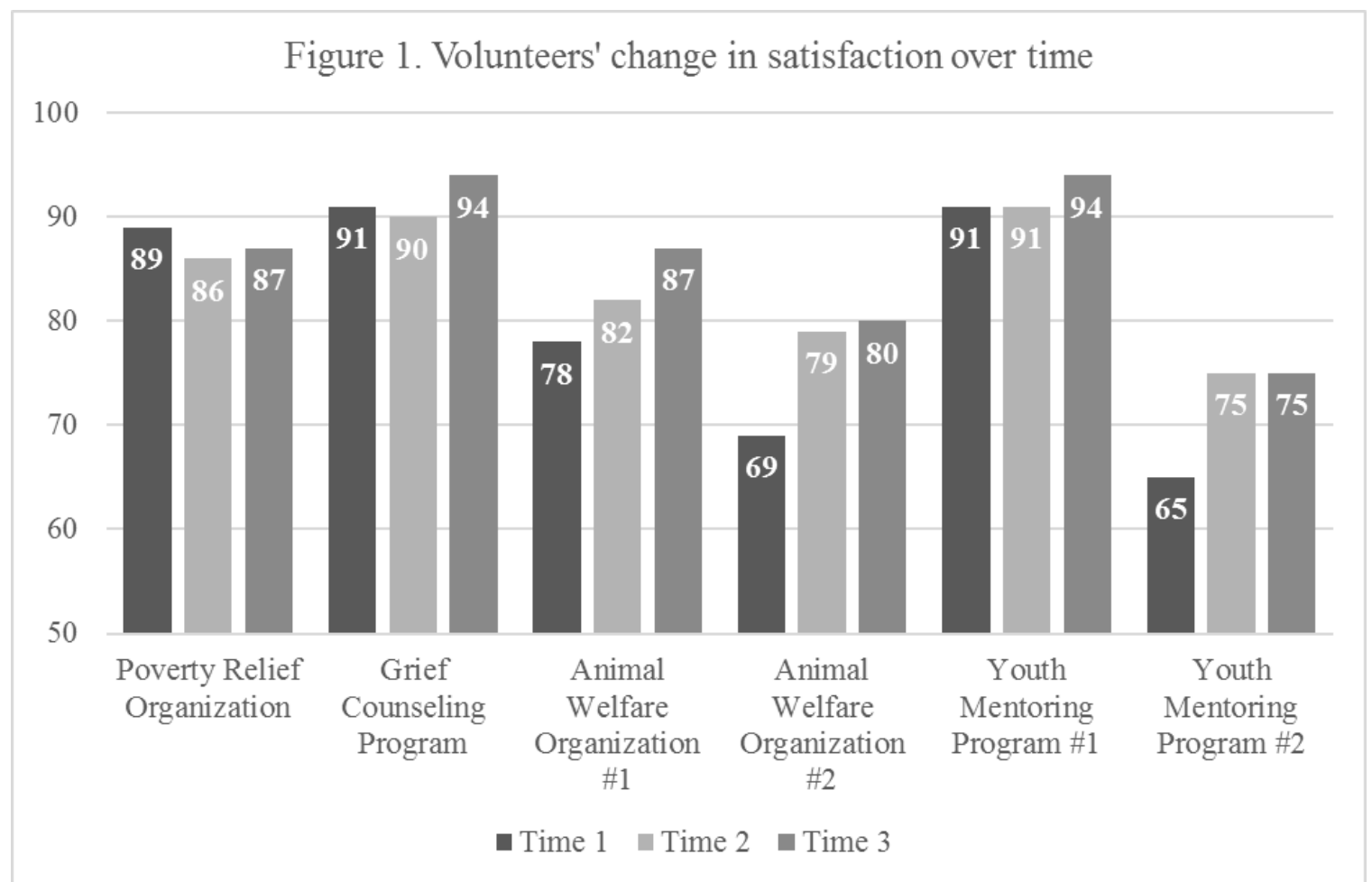

Figure 1. Volunteers' Change in Satisfaction over Time.

Increased Continuance Intentions at Client Organizations

Finally, the VPA includes questions for volunteers about their continuance intentions regarding their volunteer position. We find that most client organizations who work with VPA have a substantial proportion of volunteers who intend to continue service each year, and that the longer client organizations work with VPA, the higher the proportion of volunteers who agree that they intend to continue working with each organization. This is perhaps the biggest indication of client organization success to date. 


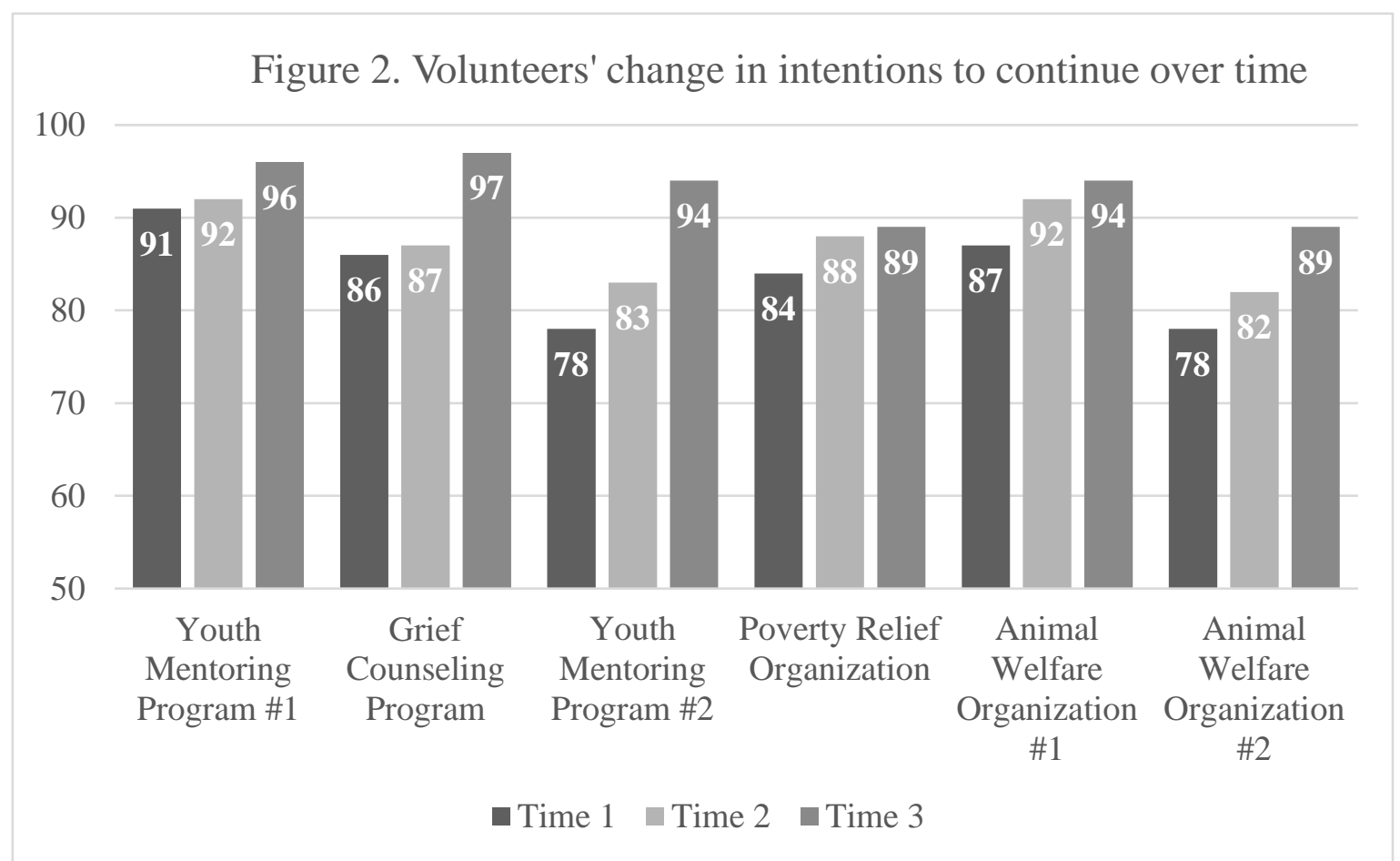

Figure 2. Volunteers’ Change in Intentions to Continue Over Time.

\section{Conclusion}

Although VPA does not perfectly meet the definition of a collective impact initiative at this time, lacking fully the benefit of a backbone organization, it does closely align with four out of five of the characteristics identified by Kania and Kramer (2011). Born of necessity in continuing to serve client organizations efficiently, steps taken to bring VPA chapters to a collective impact model over the past few years have resulted in positive changes for both the effectiveness of the VPA chapters, as well as allowed VPA to better serve a larger number of clientele. Theoretically, we reinforce that although some efforts to address social issues may not begin as collective impact, over time they may evolve into collective impact by necessity.

The future of VPA will involve greater efforts to meet a collective impact effort, with key goals including securing funding from backbone organizations, developing additional shared measurement systems to assess not only client outcomes, but student outcomes, and continuing to incorporate feedback from client organizations into the process to make it more effective. 


\section{References}

Bureau of Labor Statistics. (2016). News release: Volunteering in the United States-2015 (Publication No. USDL-14-0314). Washington, DC: U.S. Department of Labor. Retrieved from http://www.bls.gov/news.release/pdf/volun.pdf

Corporation for National and Community Service. (2016). Research: Overview statistics. Retrieved from https://www.nationalservice.gov/vcla/research

Davis, M. H., Hall, J. A., \& Meyer, M. (2003). The first year: Influences on the satisfaction, involvement, and persistence of new community volunteers. Personality and Social Psychology Bulletin, 29(2), 248-260. https://doi.org/10.1177/0146167202239050

Edmondson, J., \& Santhosh-Kumar, P. (2017). It’s about results at scale, not collective impact. Stanford Social Innovation Review - Solutions - Collaboration. Retrieved from https://ssir.org/articles/entry/its_about_results_at_scale_not_collective_impact

Eisner, D., Grimm, Robert T., Jr, Maynard, S., \& Washburn, S. (2009). The new volunteer workforce. Stanford Social Innovation Review, 7, 32-37. Retrieved from https://search-proquestcom.leo.lib.unomaha.edu/docview/217170729?accountid=14692

Flood, J., Minkler, M., Lavery, S., Estrada, J., \& Falbe, J. (2015). The collective impact model and its potential for health promotion: Overview and case study of a healthy retail initiative in San Francisco. Health Education and Behavior, 42(5), 1-15. https://doi.org/10.1177/1090198115577372

Fulbright-Anderson, K., Auspos, P., \& Anderson, A. (2001). Community involvement in partnerships with educational institutions, medical centers, and utility companies. Aspen, CO: Annie E. Casey Foundation.

Hanleybrown, F., Kania, J., \& Kramer, M. (2012, January 26). Channeling change: Making collective impact work. Stanford Social Innovation Review, 20(1). Retrieved from http://ssir.org/articles/entry/channeling_change_making_collective_impact_work.

Kania, J., Hanleybrown, F., \& Splansky Juster, J. (2014). Essential mindset shifts for collective impact. Stanford Social Innovation Review 12 (4), 2-5. Retrieved from https://ssir.org/articles/entry/essential_mindset_shifts_for_collective_impact

Kania, J., \& Kramer, M. (2011). Collective Impact. Stanford Social Innovation Review 9, (1), 3641. Retrieved from https://ssir.org/articles/entry/collective_impact

Nonprofit Association of the Midlands (n.d.). Retrieved from http://www.nonprofitam.org/? page=MissionValues.

Olien, J. L., Dunn, A, M., Lopina, E. C., \& Rogelberg, S. G. (2014). Outreach to nonprofit volunteer programs: Opportunity for impact, improving graduate education, and an invitation to 
become a part of the Volunteer Program Assessment. The Industrial Organizational Psychologist 51 (4), 51-60. Retrieved from http://www.siop.org/tip/april14/olien.pdf

Parkhurst, M., \& Preskill, H. (2014). Learning in action: Evaluating collective impact. Stanford Social Innovation Review 12 (4), 17-19. Retrieved from

https://ssir.org/articles/entry/learning_in_action_evaluating_collective_impact

Points of Light: What We Do for Nonprofits (2017). Retrieved from

http://www.pointsoflight.org /for-nonprofits

Prange, K., Allen, J. A., \& Reiter-Palmon, R. (2016). Collective impact versus collaboration: Sides of the same coin OR different phenomenon? Metropolitan Universities, 27(1), 86-96. Retrieved from https://journals.iupui.edu/index.php/muj/article/view/21119

Scales, P. C., Roehlkepartain, E. C., Neal, M., Kielsmeier, J. C., \& Benson, P. L. (2006). Reducing academic achievement gaps: The role of community service and service-learning. Journal of Experiential Education, 29(1), 38-60. https://doi.org/10.1177/105382590602900105

Turner, S., Merchant, K., Kania, J., \& Martin, E. (2012). Understanding the value of backbone organizations in collective impact: Part 1. Stanford Social Innovation Review - Solutions Collaboration. Retrieved from https://ssir.org/articles/entry/understanding_the_value_of_ backbone_organizations_in_collective_impact_1.

Urban Institute. (2004). Volunteer management capacity in America's charities and congregations: A briefing report. Washington, D.C.: The Urban Institute. Retrieved from http://webarchive.urban.org/UploadedPDF/410963_VolunteerManagment.pdf 


\title{
Author Information
}

*Sheridan B. Trent is a doctoral student studying Industrial-Organizational Psychology at the University of Nebraska at Omaha. She is also the Assistant Director of Operations for Volunteer Program Assessment at UNO. Sheridan's research interests include volunteer retention, engagement, work-life issues, and burnout.

\author{
Sheridan B. Trent \\ Department of Psychology \\ University of Nebraska at Omaha \\ 6001 Dodge Street \\ Omaha, NE 68182 \\ E-mail: strent@unomaha.edu \\ Telephone: 402-949-0227 \\ Fax: 402-554-2556
}

Kelly A. Prange is a doctoral student studying Industrial/Organizational Psychology at the University of Nebraska at Omaha. She is also the Assistant Director of Research for Volunteer Program Assessment at UNO. She is pursuing research interests within the realms of collective impact, social responsibility, and community engagement.

\author{
Kelly A. Prange \\ Department of Psychology \\ University of Nebraska at Omaha \\ 6001 Dodge St. \\ Omaha, NE 68182 \\ E-mail: kprange@unomaha.edu \\ Telephone: 402-540-1876
}

Fax: 402-554-2556

Joseph A. Allen is an Associate Professor of Industrial/Organizational Psychology at the University of Nebraska at Omaha. His engaged scholarship pursuits include the study of meetings among career and volunteer firefighters, investigating volunteer management challenges in nonprofit organizations, and the study of collaboration in the form of collective impact.

Joseph A. Allen

Department of Psychology

University of Nebraska at Omaha

6001 Dodge St.

Omaha, NE 68182

E-mail: josephallen@unomaha.edu

Telephone: 402-554-6017

Fax: 402-554-2556

*Corresponding author 